Future Directions

\title{
Gadolinium deposition disease: Initial description of a disease that has been around for a while
}

\author{
Richard C. Semelka a,*, Joana Ramalho ${ }^{\text {a,b }}$, Ami Vakharia ${ }^{\text {a }}$, Mamdoh AlObaidy ${ }^{\text {a,c }}$, Lauren M. Burke ${ }^{\text {, }}$ \\ Michael Jay ${ }^{\mathrm{d}}$, Miguel Ramalho ${ }^{\mathrm{a}, \mathrm{e}}$ \\ a Department of Radiology, University of North Carolina, Chapel Hill, NC, USA \\ ${ }^{\mathrm{b}}$ Department of Radiology, Centro Hospitalar Lisboa Central, Lisbon, Portugal \\ c Department of Radiology, King Faisal Specialist Hospital and Research Center, Riyadh, Saudi Arabia \\ ' Division of Molecular Pharmaceutics, UNC Eshelman School of Pharmacy, University of North Carolina, Chapel Hill, NC, USA \\ e Department of Radiology, Hospital Garcia de Orta, Almada, Portugal
}

\section{A R T I C L E I N F O}

\section{Article history:}

Received 26 June 2016

Accepted 30 July 2016

\section{Keywords:}

Gadolinium toxicity

Gadolinium based contrast agents

Gadolinium deposition disease

NSF

Survey

\begin{abstract}
A B S T R A C T
Purpose: To describe the clinical manifestations of presumed gadolinium toxicity in patients with normal renal function.

Materials and methods: Participants were recruited from two online gadolinium toxicity support groups. The survey was anonymous and individuals were instructed to respond to the survey only if they had evidence of normal renal function, evidence of gadolinium in their system beyond 30 days of this MRI, and no pre-existent clinical symptoms and/or signs of this type.

Results: 42 subjects responded to the survey (age: $28-69$, mean $49.1 \pm 22.4$ years). The most common findings were: central pain $(n=15)$, peripheral pain $(n=26)$, headache $(n=28)$, and bone pain ( $\mathrm{n}=$ 26). Only subjects with distal leg and arm distribution described skin thickening $(\mathrm{n}=22)$. Clouded mentation and headache were the symptoms described as persistent beyond 3 months in 29 subjects. Residual disease was present in all patients. Twenty-eight patients described symptoms following administration of one brand of Gadolinium-Based Contrast Agent (GBCA), 21 after a single GBCA administration and 7 after multiple GBCA administrations, including: gadopentetate dimeglumine, $\mathrm{n}=9$; gadodiamide, $\mathrm{n}=4$; gadoversetamide, $\mathrm{n}=4$; gadobenate dimeglumine, $\mathrm{n}=4$; gadobutrol, $\mathrm{n}=1$; gadoteridol, $\mathrm{n}=2$; and unknown, $\mathrm{n}=4$.

Conclusions: Gadolinium toxicity appears to arise following GBCA administration, which appears to contain clinical features seen in Nephrogenic Systemic Fibrosis, but also features not observed in that condition.
\end{abstract}

(c) 2016 Elsevier Inc. All rights reserved.

\section{Introduction}

Gadolinium related toxicity has been recognized for at least 10 years, with the initially described condition being nephrogenic systemic fibrosis (NSF). NSF is a debilitating and potentially life-threatening disease that was first recognized in 1997 in 15 dialyzed patients and later described in 2000 [1]. Almost a decade later, the association between the described changes and the administration of Gadolinium-based contrast agents (GBCAs) was

\footnotetext{
* Corresponding author at: Department of Radiology, UNC at Chapel Hill, CB 7510, 2001 Old Clinic Bldg., Chapel Hill, NC, 27599-7510. Tel.: +1 919966 9676; fax: +1 919 8437147.

E-mail address: richsem@med.unc.edu (R.C. Semelka).
}

established by groups of nephrologists, initially Grobner et al. [2] and subsequently Marckmann et al. [3]. The combination of limiting or avoiding the use of GBCAs in subjects with advanced renal failure and employing more stable GBCAs greatly reduced the incidence of this disease with no new cases reported after 2009 [4].

This led many to believe that: 1 ) the most stable GBCAs were extremely safe and did not cause disease, and 2) subjects with normal renal function did not develop gadolinium related toxicity. However, patients with normal renal function have described severe disease that arose shortly after the administration of GBCAs $[5,6]$. A first description of a presumed toxicity related to GBCA administration has been recently published [5]. It appears that patients with normal renal function may exhibit severe symptomatology, beyond the time frame of severe acute adverse events, 
related to the administration of GBCAs [7]. The purpose of our study was to access patients who report severe symptomatology following GBCA administration, to assess the various manifestations and to attempt to identify which GBCAs may be most responsible for the disease.

\section{Methods}

Institutional review board approval was obtained for this Health Insurance Portability and Accountability Act (HIPAA) - compliant prospective study. The survey was anonymous and all participants were recruited from online gadolinium toxicity support groups. All participants of the survey were informed of the purpose of the study. An electronic link to the survey was posted to a private blog [8] (MRI-Gadolinium-Toxicity support group) that discusses gadolinium toxicity, and a public Gadolinium Toxicity Facebook page [9].

The survey was posted online and consisted of 18 questions that were completed between November 21 and November 30, 2015 (Appendix A). Participants had the option to leave any question unanswered. All responses were anonymous. For the survey, participants were asked to confirm the number of GBCA doses and if possible, the types of GBCA received. In addition, the survey also asked which symptoms and signs were present, how soon after intravenous administration of the GBCAs symptoms began, and the duration of the symptoms.

The senior author of this study separately requested anonymized data from the leaders of the two patient advocacy groups to provide information on the number of patients who experienced signs and/ or symptomatology following the administration of only 1 brand of contrast agent, if this data was pre-existent in their records, and whether symptoms arose after a single or multiple uses of the agent. Substantial, but not complete overlap with the survey respondents was anticipated.

Inclusion criteria were as follows: (a) subjects with normal renal function (eGFR $>60 \mathrm{~mL} / \mathrm{min}$ per $1.73 \mathrm{~m}^{2}$ ) who experienced severe and persistent symptoms with onset from 1 to 365 days following GBCA administration; and (b) who had laboratory evidence of presence of gadolinium in their body beyond 30 days following the inciting magnetic resonance imaging (MRI) examination. Finally, direct medical examination was performed by a physician with expertise in NSF, on three random participants, one

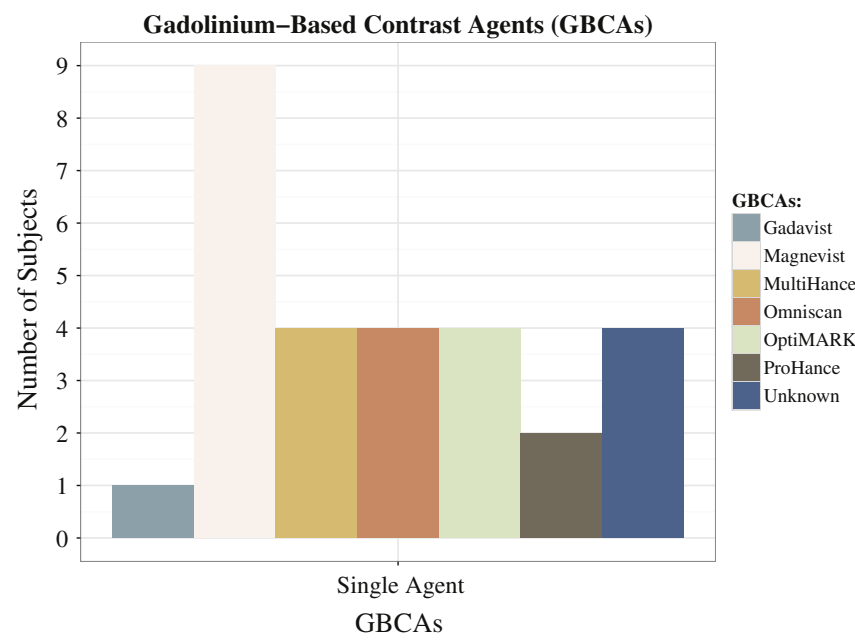

Fig. 1. Distribution of subjects, who performed all contrast-enhanced MRI studies with one single GBCA, according with GBCA administered. in the early stage and two in the late stage, to verify physical exam findings.

\subsection{Statistical analysis}

Descriptive statistics were used for demographics, number and types of GBCAs, kidney function, tissue tests, sites and patterns of pain and other somatic reactions and/or changes.

$\mathrm{R}$, a language and environment for statistical computing ( $\mathrm{R}$ Core Team, Vienna, Austria), was used for all statistical computing.

\section{Results}

Forty-two participants responded to this survey (27 women, 14 men; and 1 participant did not specify). Forty were Caucasian white and 2 were Hispanic white.

One participant reported history of renal insufficiency. This patient reported a remote history of renal insufficiency, which preceded the inciting MRI. At the time of the inciting MRI, the patient had normal renal function. The age of onset ranged from 28 to 69, mean $49.1 \pm 22.4$ years.

Forty-one participants had evidence of gadolinium presence beyond 1 month after exposure. Gadolinium was documented in urine in 41 participants and thyroid tissue in a single patient. Elevated gadolinium in blood was seen in 8 subjects, and in other tissues in 5 subjects, including thyroid $(\mathrm{n}=1)$, scalp $(\mathrm{n}=1)$, skin $(\mathrm{n}=2)$ and hair $(\mathrm{n}=2)$.

Among the 42 subjects, 28 described symptoms following administration of one brand of GBCA (Fig. 1). Twenty-one subjects stated the symptomatology started after a first-time administration [gadopentetate dimeglumine (Magnevist ${ }^{\circledR}$; Bayer HealthCare Pharmaceuticals, Wayne, New Jersey), $\mathrm{n}=7$; gadodiamide (Omniscan ${ }^{\circledR}$; GE Healthcare, Piscataway, New Jersey, $\mathrm{n}=3$; gadobenate dimeglumine (MultiHance $₫$; Bracco Diagnostics, Princeton, New Jersey), $\mathrm{n}=3$; gadoversetamide (OptiMARK ${ }^{\circledR}$; Mallinckrodt, St. Louis,

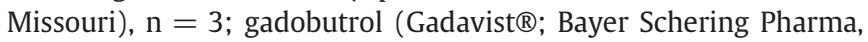
Berlin, Germany), $\mathrm{n}=1$; Unknown, $\mathrm{n}=4$ ]. The remaining seven subjects received multiple doses of a single agent [Magnevist $\AA, \mathrm{n}=2$; Omniscan ${ }^{\circledR}, \mathrm{n}=1$; MultiHance ${ }^{\circledR}, \mathrm{n}=1$; OptiMARK ${ }, \mathrm{n}=1$; gadoteridol (ProHance ${ }^{\circledR}$; Bracco Diagnostics), $n=2$ ]. The remaining subjects had symptoms after multiple GBCAs exposures with different agents.

The separate inquiry of the leaders of the two major patient advocacy groups revealed that in the database of their members, 24 subjects developed unconfounded cases of disease related with the administration of a single GBCA. Seventeen subjects described symptomatology following one administration (Magnevist ${ }^{\circledR}, \mathrm{n}=6$; Omniscan ${ }^{\circledR}, \mathrm{n}=3$; MultiHance ${ }^{\circledR}, \mathrm{n}=4$; Optimark $\AA, \mathrm{n}=4$ ). Seven subjects received multiple doses of only one agent (Magnevist ${ }^{\circledR}, \mathrm{n}=2$; Omniscan ${ }^{\circledR}$, $\mathrm{n}=1$; MultiHance ${ }^{\circledR}, \mathrm{n}=2$; ProHance ${ }^{\circledR}, \mathrm{n}=2$ ).

\subsection{Pain}

Among the 42 subjects, pain lasted for less than 3 months, including: central pain $(n=6)$, peripheral pain $(n=9)$, headache $(n=4)$, bone pain $(n=7)$ and other site $(n=9)$. Pain lasted beyond 3 months, and persisted to the time of the survey, including: central pain $(n=15)$, peripheral pain $(n=26)$, headache $(n=28)$ and bone pain $(n=26)$ and other pain location $(n=25)$ (Fig. 2). Often the same patient described more than one type of pain.

Pain at presentation was described as sharp pain/"pins and needle" in 25 subjects (15 central, 10 peripheral) and intense burning in 15 (10 central, 5 peripheral). The distribution of pain 
appeared to shift from central to peripheral in 20 subjects with time. In 10 patients who suffer from peripheral leg and arm pain from the start, the character of pain changed to an intense burning in all patients.

\subsection{Skin changes}

Tissue thickening arose from 2 weeks to 2 months following GBCA administration. Only subjects with distal leg and arm distribution described skin thickening $(n=22)$, which was confined to the distribution of the pain. Skin discoloration was seen in 28 subjects (Fig. 2).

\subsection{Musculoskeletal manifestations}

Bone pain was present in 33 subjects. Joint stiffness was present in 33 subjects, muscle spams in 30 subjects, buzzing sensation in 24 subjects, fatigue in 36 subjects and skin edema in 22 subjects (Fig. 2).

\subsection{Central neurological findings}

Clouded mentation was a symptom described as persistent beyond 3 months in 29 subjects (all of whom also had headache). Metallic taste was reported in 19 subjects as a prominent persistent metallic taste following the inciting gadolinium administration.
This taste arose immediately to 1 day following the administration and persisted for up to or more than one month.

\subsection{Persistence of disease}

In all subjects $(n=42)$ residual disease, symptoms were noted to diminish over time (ranging from 4 months to 8 years), but continued to interfere with daily life. These patients suffer from skin thickening $(n=29)$ (self-characterized as rubbery or spongy skin thickening of the fingers in 20 subjects), and moderate pain. Residual pain was observed in 31 subjects.

All 42 subjects responded that they possessed the symptoms requested on the survey, and additional 37 subjects added additional persisting symptoms (Fig. 3).

\section{Discussion}

Our results show that many of the respondents' reported signs and symptoms are consistent among subjects, and include various findings similar, but less severe than found in NSF [10]. Based on these results, we propose a name for this presumed disease process in subjects with normal renal function and gadolinium toxicity, Gadolinium Deposition Disease (GDD). At least 60\% of our subjects showed a glove-and-sock distribution of disease associated with intense sharp "pins and needles" or burning pain, and skin changes, resembling NSF [11-13]. Other examples of similar but less severe changes compared to NSF include: tissue in NSF is often described
A

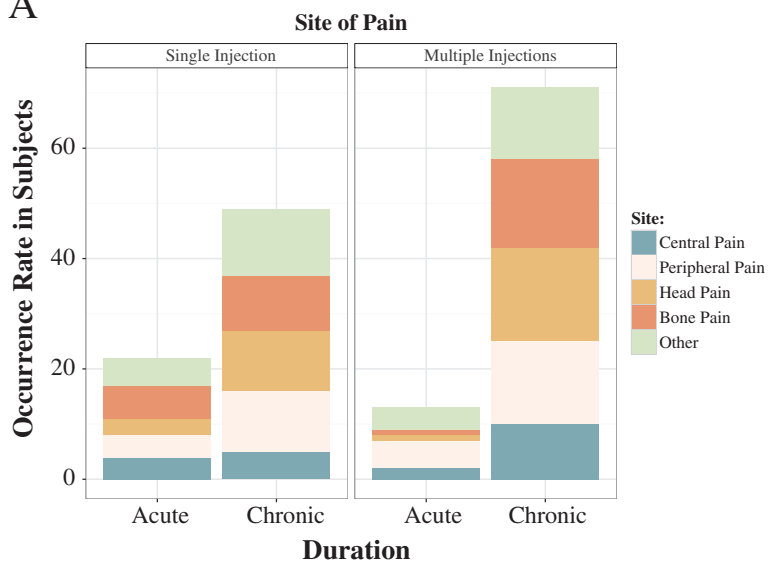

$\mathrm{C}$

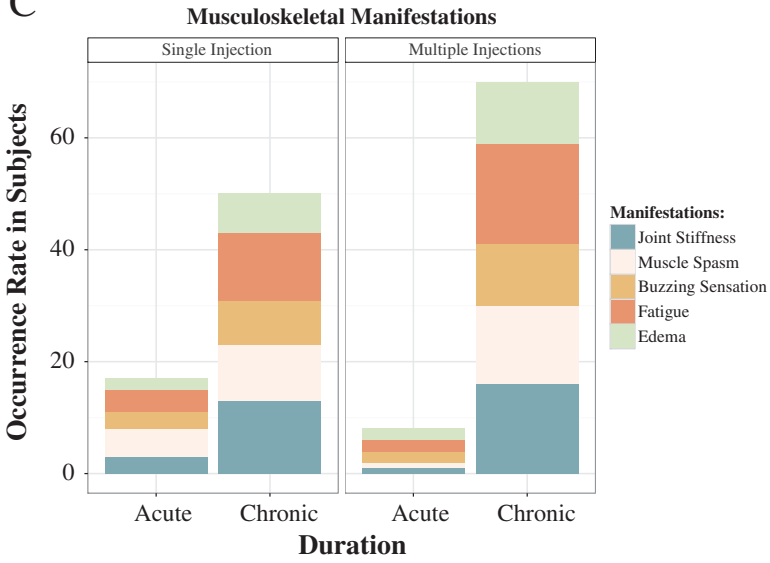

B

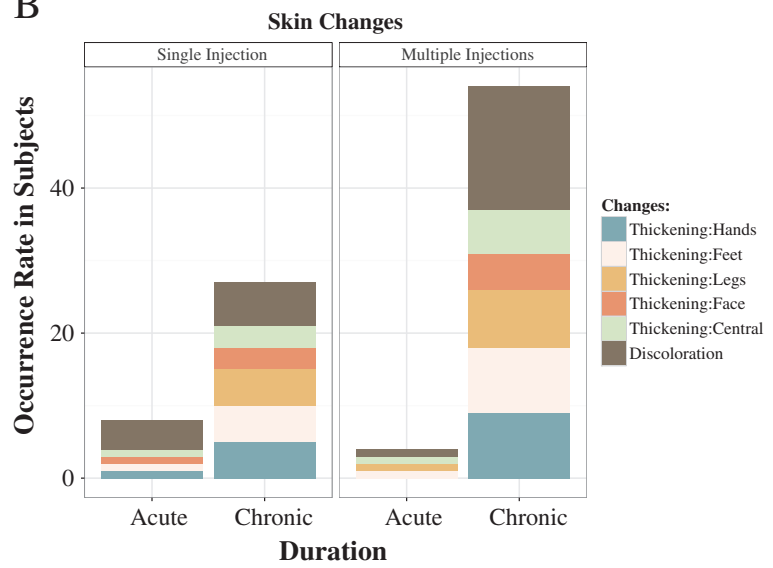

$\mathrm{D}$

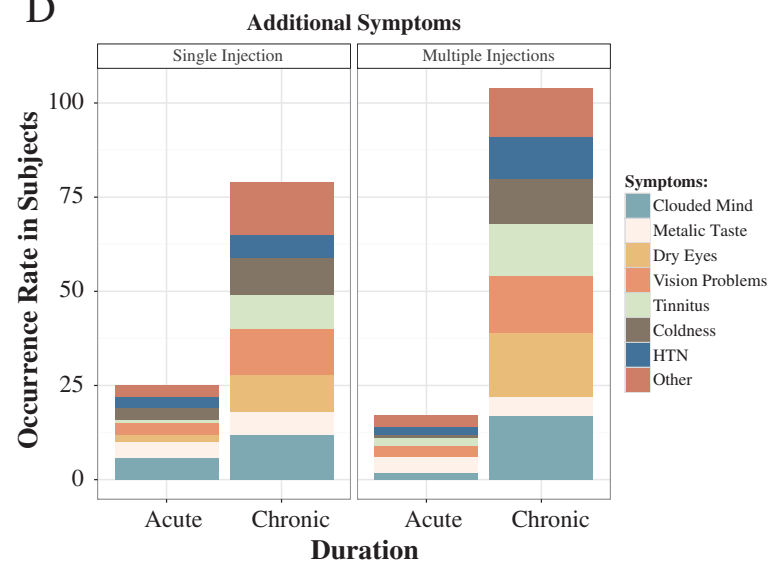

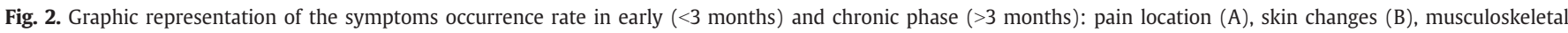
manifestations (C) and additional symptoms (D). 


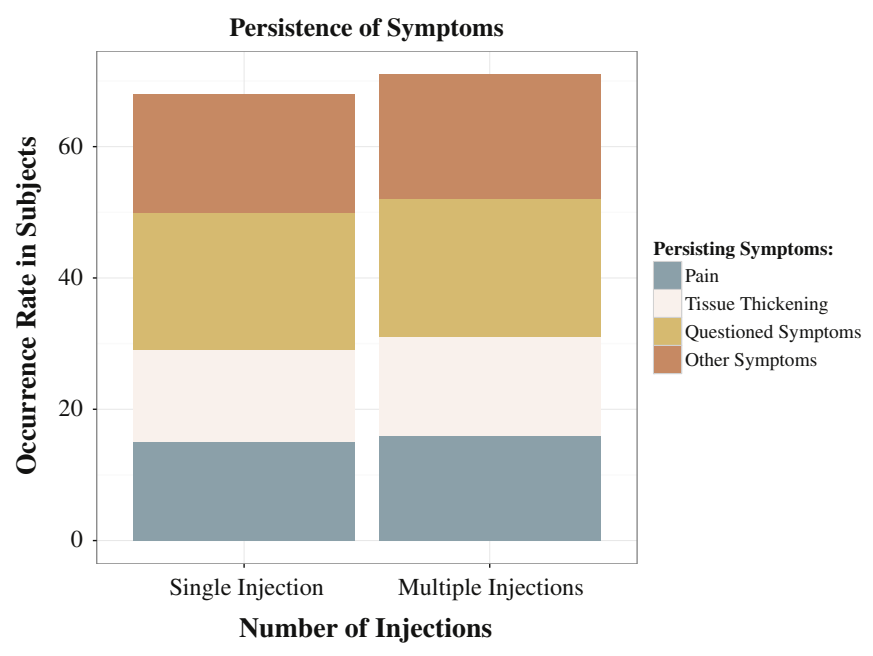

Fig. 3. Graphic representation of the occurrence rate of persistent symptoms (symptoms occurring up to the day of the survey).

as woody and joint contractions severe, whereas subjects in our survey have reported as spongy or rubbery, and joint flexures minimal. Fifteen subjects (35\%) reportedly exhibited persistent central torso (trunk) pain and $22(52 \%)$ patients reported distal leg and arm pain along tissue thickening also comparable with NSF. A 2011 report of gadolinium presence in tissues in subjects with NSF, described two control groups of subjects with normal renal function, and previous GBCA administration, who also demonstrated gadolinium in their tissue samples [14].

Bone pain was a commonly reported finding in our survey. Intense headache and clouded mentation were commonly reported also. This feature appears more distinctive for this presumed GDD, as this has not been generalized recognized in the NSF population.

It is not unreasonable that physicians may be skeptical that subjects with normal renal function may develop toxic disease to gadolinium. Sieber et al. [15] reported on the occurrence of NSF-like skin condition development in the rat model with normal renal function studying multiple GBCAs, who received large doses of agent. In the clinical setting, many humans have also undergone multiple serial examinations with GBCA, which is not uncommon for some disease processes (e.g. Multiple Sclerosis patients), recreating the circumstance of this animal study. A case report of this type has been recently reported in which the subject had received 61 administrations of GBCA [16]. This case report challenged published literature, suggesting that in patients with normal renal function, exposure to GBCAs in extremely high cumulative doses can lead to significant gadolinium deposition in the skin. Interestingly this patient had no history of skin disorders and did not have a history of nephrogenic systemic fibrosis but did have severe joint contractures of unknown etiology.

In reviewing the agents the suspected causative GBCAs whose unconfounded use resulted in reported symptoms, were also those more related to NSF, in $83 \%$ from our survey data and $75 \%$ from the data provided by the patient action groups. However, some individuals also reportedly developed this disease following MultiHance ${ }^{\circ}$, a linear agent with intermediate stability [17], but also after macrocyclic agents, which are the most stable. In this survey, the only agent that was not associated with presumed toxicity was Dotarem ${ }^{\circledR}$. It should however be acknowledged that Dotarem ${ }^{\circledR}$ is the most recently FDA-approved GBCA and has probably the lowest number of doses administered in the USA, where our data is acquired from.

It may be that a greater range of immune system elements may be activated in this normal renal function group compared to renal failure patients who develop NSF. It is possible that the polypeptides that result in acute adverse events form a critical component of the entire immune response to these agents, in addition to the later cell-based immune response, described with CD34+ fibroblasts in NSF [18]. This hypothesis relies on the observation that all GBCAs, regardless of stability, elicit acute adverse events [19]. Along this line of explanation, Wermuth et al. [20] found that both linear and macrocyclic agents stimulated release of numerous chemokines, cytokines, and growth factors, which are mediators of acute reactions.

Based on this survey we believe the critical findings are the presence of gadolinium in the body, which we randomly chose beyond 30 days, combined with at least 3 of the following features, that must have shown onset only after the administration of GBCA: i) central torso pain, ii) headache and clouded mentation, iii) peripheral leg and arm pain, iv) peripheral leg and arm thickening and discoloration, and v) bone pain.

Based on the veracity of this survey that subjects with normal renal function may develop severe disease following administration of GBCAs, is on the surface very worrisome. It should however be noted that at present the number of subjects with this severe reaction may be relatively few and may have a low occurrence rate, comparable to that of catastrophic acute adverse reactions for gadolinium- and iodine-based contrast agents [19,21-23].

There are various limitations of our study. Major problems include that it is a survey and relies on knowledge and integrity of the respondents. Despite that a survey provides all the participants with a standardized stimulus, eliminating researcher's own biases, it is recognized that self-report studies may have validity problems. Although the study is subjective, in that we rely on patient descriptions, it should also be appreciated that there was a generally common pattern of symptomatology. A control group of subjects who received multiple administrations of GBCAs, but who do not have symptoms would be helpful. As an anonymous survey with predefined questions, we neither asked nor had access to the clinical indications for the MR examinations. It should be stressed that our survey emphasized that the clinical findings they attribute to gadolinium toxicity must be new findings that were not present prior to contrast administration. Moreover, no patient took medications other than GBCAs that could be possible causes for the reported signs and symptoms.

Skin histology was also not evaluated, which would also be of interest. A recent report by Gathings et al. [24] described histologic features of a new condition that they observed in patients with normal renal function, that they called GadoliniumAssociated Plaques. These were erythematous plaques containing sclerotic bodies in the skin following GBCA administrations that previously were thought to be pathognomonic for NSF. It would be interesting to learn if these patients were symptomatic. Finally, our hypothesis that GDD combines both acute and chronic immune mechanisms has not been confirmed histologically or biochemically.

In summary, we report a presumed GBCA toxicity in patients with normal renal function, that we term GDD. These patients reportedly experienced severe and persistent symptoms that might resemble a milder form of NSF, but may also possess some distinct features. In this survey the weakest chelates were the agents most likely to cause this reported toxicity, but more stable agents were also implicated in it. In the very least our study emphasizes that further prospective investigation is needed to verify this condition. 
Appendix A. Survey

\section{SURVEY}

Q1 Please choose your gender.

O Female (1)

O Male (2)

Q2 Please enter your age.

Q3 Please enter your race.

Q4 Do you have a fluid/tissue tests showing presence of elevated gadolinium taken beyond 1 month of gadolinium injection. Check all that apply.

口 Urine (1)

$\square$ Blood (2)

Tissue: Please enter location on body (3)

Q5 Kidney Function: Normal/near normal at the time of MRI?

प Yes (1)

$\square$ No (2)

Q6 Did you acquire this disease after 1 injection?

Y Yes. If so, what was the contrast agent given? (1)

O No, it was after multiple injections. Please see following question. (2)

Q7 If you acquired the disease after multiple injections, was the same contrast agent given?

Yes. If yes, which contrast agents were given each time? (1)

No. If no, please list the contrast agents given if possible. (2)

Q8 How long after the gadolinium injection did you start feeling symptoms, did the disease begin in days, months, years? Please specify.

Q9 Pain location - Initial (less than 3 months). Check all that apply.

Central torso pain (1)

- Peripheral sock and glove pain (lower half of the arms and/or lower half the legs) (2)

Head pain (3)

$\square$ Bone pain (4)

None (5)

Other: Please specify (6) 
Q10 Type of pain - Initial (less than 3 months). Check all that apply.

- Sharp pins and needle (1)

Burning (2)

a None (3)

Other: Please specify (4)

Q11 Other Initial Signs/Symptoms (less than 3 months) - Check all that apply

口 Clouded mind/Brain fog (1)

Hand: skin or tissue thickening (2)

Foot: skin or tissue thickening (3)

Leg: skin or tissue thickening (4)

Face: skin or tissue thickening (5)

- Central body: skin or tissue thickening (6)

- Skin discoloration/hyperpigmentation. Please specify location. (7)

Joint stiffness. What location of the body? Please specify location. (8)

Metal taste in mouth (9)

Dry eyes (10)

V Vision changes (11)

प Muscle spasms (12)

- Vibrating/buzzing sensation in muscles (13)

Tinnitus (14)

G Fatigue (15)

L Low body temperature (16)

B Blood pressure (abnormal increases or decreases) (17)

- Edema (swelling in extremities (18)

ㄱone (19)

Other: Please specify (20)

Q12 Pain - Chronic (greater than 3 months). Please check all that apply.

C Central torso pain (1)

- Peripheral sock and glove pain (lower half of the arms and/or lower half of the legs) (2)

Head pain (3)

$\square$ Bone pain (4)

None (5)

$\square$ Other: Please specify (6)

Q13 Type of Pain - Chronic (greater than 3 months). Please check all that apply. Sharp pins and needles (1)

ㅁ Burning (2)

․ None (3)

Other: Please specify (4) 
Q14 Other Chronic Signs/Symptoms (greater than 3 months) - Check all that apply.

C Clouded mind/Brain fog (1)

Hand: skin or tissue thickening (2)

Foot: skin or tissue thickening (3)

Leg: skin or tissue thickening (4)

Face: skin or tissue thickening (5)

Central body: skin or tissue thickening (6)

- Skin discoloration/hyperpigmentation. Please specify location. (7)

$\square$ Joint stiffness. Please specify location (8)

Metal taste in mouth (9)

Dry eyes (10)

V Vision changes (11)

口 Muscle spasms (12)

- Vibrating/buzzing sensation in muscles (13)

口 Tinnitus (14)

a Fatigue (15)

Low body temperature (16)

- Blood pressure (abnormal increases or decreases) (17)

口 Edema (swelling in extremities) (18)

口 None (19)

Other: Please specify (20)

Q15 Do you still have persisting problems

O Yes. (If yes, please enter how long). (1)

O No (2)

Q16 If yes to the previous question, which signs/ symptoms? Check all that apply 口 Pain (1)

- Peripheral sock and glove pain (lower half of the arms and/or lower half of the legs) (2)

Other: Please specify (3)

Q17 Are problems skin or tissue thickening / stiffness?

O Yes. If yes please inform if skin or tissue thickening is in peripheral sock and glove distribution (lower half of the arms and/or legs) or other (please specify) (1)

O No. (2)

Q18 Do you feel the previous questions have allowed you to accurately and adequately describe your symptoms?

O Yes (1)

O No. Please use box below to provide additional information. (2) 


\section{References}

[1] Cowper SE, Robin HS, Steinberg SM, Su LD, Gupta S, LeBoit PE. Scleromyxoedema-like cutaneous diseases in renal-dialysis patients. Lancet 2000;356(9234):1000-1.

[2] Grobner T. Gadolinium - a specific trigger for the development of nephrogenic fibrosing dermopathy and nephrogenic systemic fibrosis? Nephrol Dial Transplant 2005;21(4):1104-8.

[3] Marckmann P. Nephrogenic systemic fibrosis: suspected causative role of gadodiamide used for contrast-enhanced magnetic resonance imaging. J Am Soc Nephrol 2006;17(9):2359-62.

[4] Altun E, Martin DR, Wertman R, Lugo-Somolinos A, Fuller ER, Semelka RC. Nephrogenic systemic fibrosis: change in incidence following a switch in gadolinium agents and adoption of a gadolinium policy - report from two U.S. universities. Radiology 2009;253(3):689-96.

[5] Burke LM, Ramalho M, AlObaidy M, Chang E, Jay M, Semelka RC. Self-reported gadolinium toxicity: a survey of patients with chronic symptoms. Magn Reson Imaging 2016;34(8):1078-80.

[6] Ramalho J, Semelka RC, Ramalho M, Nunes RH, AlObaidy M, Castillo M. Gadolinium-based contrast agent accumulation and toxicity: an update. Am J Neuroradiol 2015 [Epub ahead of print].

[7] Toxicity G. A survey of the chronic effects of retained gadolinium from contrast MRIs. https://gdtoxicity.files.wordpress.com/2014/09/gd-symptom-survey.pdf. [Accessed November 1st, 2015].

[8] http://gadoliniumtoxicity.com. [Accessed December 2015].

[9] https://www.facebook.com/gadoliniumtoxicity/. [Accessed December 2015].

[10] Heverhagen JT, Krombach GA, Gizewski E. Application of extracellular gadolinium-based MRI contrast agents and the risk of nephrogenic systemic fibrosis. RöFo 2014;186(7):661-9.

[11] Fretellier N, Idée J-M, Guerret S, Hollenbeck C, Hartmann D, González W, et al. Clinical, biological, and skin histopathologic effects of ionic macrocyclic and nonionic linear gadolinium chelates in a rat model of nephrogenic systemic fibrosis. Investig Radiol 2011;46(2):85-93.
[12] Cowper SE, Bucala R, Leboit PE. Nephrogenic fibrosing dermopathy/nephrogenic systemic fibrosis - setting the record straight. Semin Arthritis Rheum 2006;35(4):208-10.

[13] Cowper SE. Nephrogenic systemic fibrosis: a review and exploration of the role of gadolinium. Adv Dermatol 2007;23:131-54.

[14] Christensen KN, Lee CU, Hanley MM, Leung N, Moyer TP, Pittelkow MR Quantification of gadolinium in fresh skin and serum samples from patients with nephrogenic systemic fibrosis. J Am Acad Dermatol 2011;64(1):91-6.

[15] Sieber MA, Lengsfeld P, Frenzel T, Golfier S, Schmitt-Willich $H$, Siegmund F, et al. Preclinical investigation to compare different gadolinium-based contrast agents regarding their propensity to release gadolinium in vivo and to trigger nephrogenic systemic fibrosis-like lesions. Eur Radiol 2008;18(10):2164-73.

[16] Roberts DR, Lindhorst SM, Welsh CT, Maravilla KR, Herring MN, Braun KA, et al. High levels of gadolinium deposition in the skin of a patient with normal renal function. Investig Radiol 2016;51(5):280-9.

[17] http://www.esur.org/guidelines/. [Accessed December 2015].

[18] Sieber MA, Steger-Hartmann T, Lengsfeld P, Pietsch H. Gadolinium-based contrast agents and NSF: evidence from animal experience. J Magn Reson Imaging 2009;30(6):1268-76

[19] ACR Manual on Contrast Media. Version 10.1. ACR Committee on Drugs and Contrast Media; 2015

[20] Wermuth PJ, Jimenez SA. Induction of a type I interferon signature in normal human monocytes by gadolinium-based contrast agents: comparison of linear and macrocyclic agents. Clin Exp Immunol 2013;175(1):113-25.

[21] Jung J-W, Kang H-R, Kim M-H, Lee W, Min K-U, Han M-H, et al. Immediate hypersensitivity reaction to gadolinium-based MR contrast media. Radiology 2012;264(2):414-22.

[22] Prince MR, Zhang H, Zou Z, Staron RB, Brill PW. Incidence of immediate gadolinium contrast media reactions. AJR Am J Roentgenol 2011;196(2):W138-43.

[23] Abujudeh HH, Kosaraju VK, Kaewlai R. Acute adverse reactions to gadopentetate dimeglumine and gadobenate dimeglumine: experience with 32,659 injections. Am J Roentgenol 2010;194(2):430-4.

[24] Gathings RM, Reddy R, Santa Cruz D, Brodell RT. Gadolinium-Associated Plaques. A new, distinctive clinical entity. JAMA Dermatol 2015;151(3):316-9. 